\title{
Development of an Integrated Durability Assessment Methodology of Thermal Mortars Applied in Multi-layer Systems
}

\author{
Joana Maia ${ }^{1 \mathrm{a}}$, Nuno M. M. $\operatorname{Ramos}^{1 \mathrm{~b}}$ and Rosário Veiga ${ }^{2}$ \\ ${ }^{1}$ CONSTRUCT (LFC), Faculty of Engineering of University of Porto, R. Dr. Roberto Frias, s/n 4200-

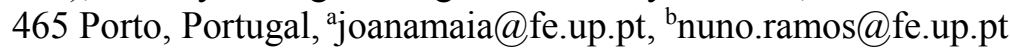 \\ ${ }^{2}$ National Laboratory for Civil Engineering (LNEC), Av. do Brasil, 101 1700-066 Lisboa, Portugal, \\ rveiga@lnec.pt
}

\begin{abstract}
A gap in the durability assessment of thermal mortars applied in multi-layer systems was observed. The existing standardisation for the durability assessment of hardened mortars does not include a consistent evaluation of thermal coatings applied in multilayer systems, which motivated the development of a new durability assessment methodology. The determination of the physical, hygrothermal and mechanical properties allowed deepening the knowledge of thermal mortars, contributing to develop more reliable simulations. The existing durability methodologies applicable to one-coat mortars and those applicable to thermal multilayer systems (such as ETICS - External Thermal Insulation Composite Systems) are suitable to be adapted to thermal rendering and plastering systems since they present some similar characteristics. The methodology takes into account the material characteristics and specific requirements, such as the application and climatic conditions. The knowledge of these parameters allows the definition of representative accelerated ageing cycles of the relevant degradation mechanisms. The combination of existing procedures with hygrothermal simulation allowed the development of accelerated ageing cycles, taking into account the European climatic context. The existing procedures allowed analysing several degradation mechanisms, but the fixed parameters are not transversal to different climates. The developed methodology allows a realistic durability evaluation since the ageing cycles are adapted to thermal mortars and real climate conditions, contrary to the existing standardised procedures.
\end{abstract}

Keywords: Thermal Mortars, Durability, Accelerated Ageing, Experimental Tests, Methodology.

\section{Introduction}

One of the seven objectives defined by the European Mortar Industry Organization (EMO) is to "raise awareness for sustainability", emphasizing the ecology of mineral mortars and the need to promote the advantages of using this type of products, their durability and lack of hazardous substances in comparison with other materials on the market (EMO, 2013). However, the concept of eco-design should relate to not only the environmental ecology issue but also the quality of life of the users of such products or services. According to Erhorn, Hansen, Kaan, and Barker (2007), eco-buildings can reduce energy consumption and enhance the use of renewable energies, bio-climatically designed. This reduction could be achieved taking into account sun exposure, architectural requirements, increase of the thermal insulation and tightness of the building, throughout new products, constructive solutions and viable technologies.

The use of thermal mortars in multi-layer façade systems influences several aspects of the sustainability of buildings as the fulfilment of several basic principles stated above. As such, 
the continuous interest in the development of sustainable solutions with thermal enhanced properties, incorporating different types of wastes (industrial or plant origin), allows the development of new solutions with less harmful impact to environment than traditional construction materials (Matias, Faria, and Torres, 2014; Skoczylas and Rucińska, 2018; Torres and Matias, 2016). To improve the thermal behaviour of buildings, different products incorporating lightweight aggregates with low density and thermal conductivity have appeared on the market. Thermal renders and plasters continue to awaken the interest of the researchers (Borges, Flores-Colen, and de Brito, 2018; Nosrati and Berardi, 2018; Soares, de Fátima Júlio, Flores-Colen, Ilharco, and Brito, 2018; Westgate, Paine, and Ball, 2018).

Thermal mortars applied in multi-layer systems frequently have at least two different layers: thermal mortar and finishing coating. Thermal mortars are addressed in EN 998-1 (CEN, 2010), which refers to EN 1015-21 for durability test methods in mortars (CEN, 2002). However, this standard is only applicable to one-coat renders, not taking into account the different material layers (i.e. the system as a whole). The durability assessment methodologies preconized in the ETAG 004 (EOTA, 2013), are directly applied to ETICS. Consequently, the existing procedures, such as the ones provided by EN 1015-21 and ETAG 004, do not allow a feasible durability assessment of thermal rendering and plastering systems (see Figure 1).
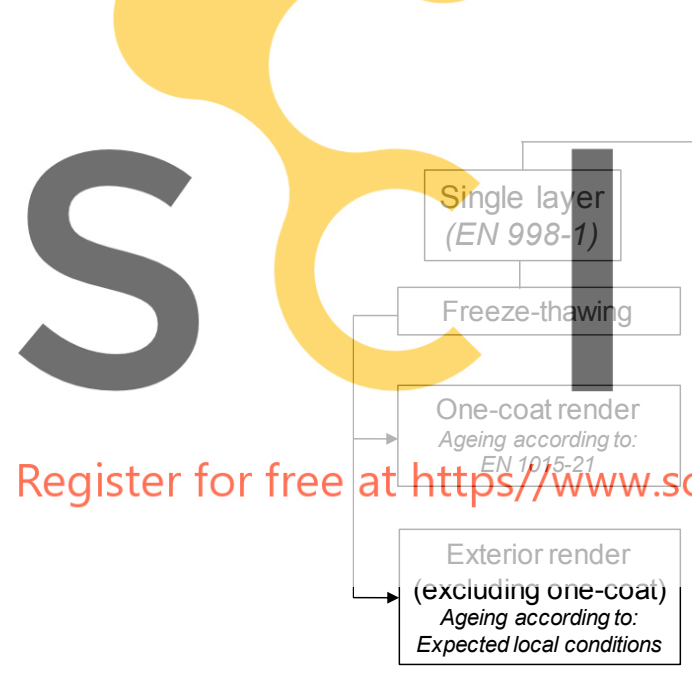

Durability assessment of thermal wall systems

Register for free at htteN $1055-21$ un scipedia $A_{w} \leq 0.5 \mathrm{~kg} / \mathrm{m}^{2}$ (reinforced base coat) $\quad$ Development of
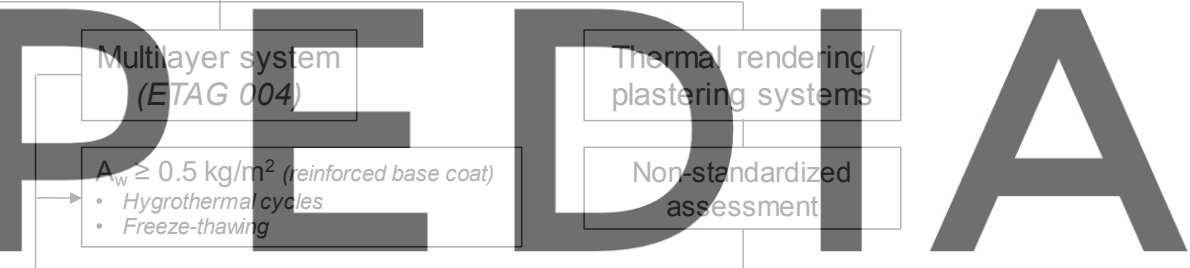

Exterior render

Ageing according to:

Expected local condition

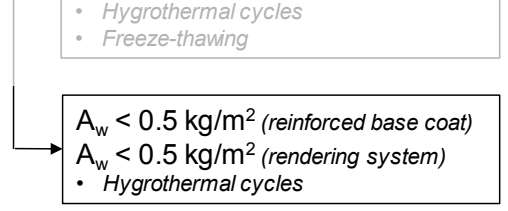

assessment

methodologies

Figure 1. Framework of existing durability assessment methodologies, applicable to renders and thermal multilayer systems.

In order to obtain more durable building envelopes, the durability assessment should focus on the required performance, especially the climatic conditions (Pedro Júlio, Paiva, and Dominguez, 2013). Since construction materials are subjected to several degradation agents, which promote different degradation levels, their selection presents an important role in the durability of the system (ABCB, 2006; Gaspar and Brito, 2008). In that way, the objective of this paper consists of presenting an integrated proposal of a new durability assessment methodology applicable to thermal mortars in multilayer systems. 


\section{A New Durability Assessment Methodology - Methodological Process}

Being the EN 1015-21 and ETAG 004 methodologies applicable to renders and thermal multilayer systems (ETICS), they may be adapted to thermal rendering and plastering systems, since they present some similar characteristics. This adaptation could give reliable data and inputs to the development of durability assessment methodologies directly applicable to thermal rendering and plastering systems. As such, a methodological process for the durability assessment of the systems in study was developed, as explained in Figure 2.

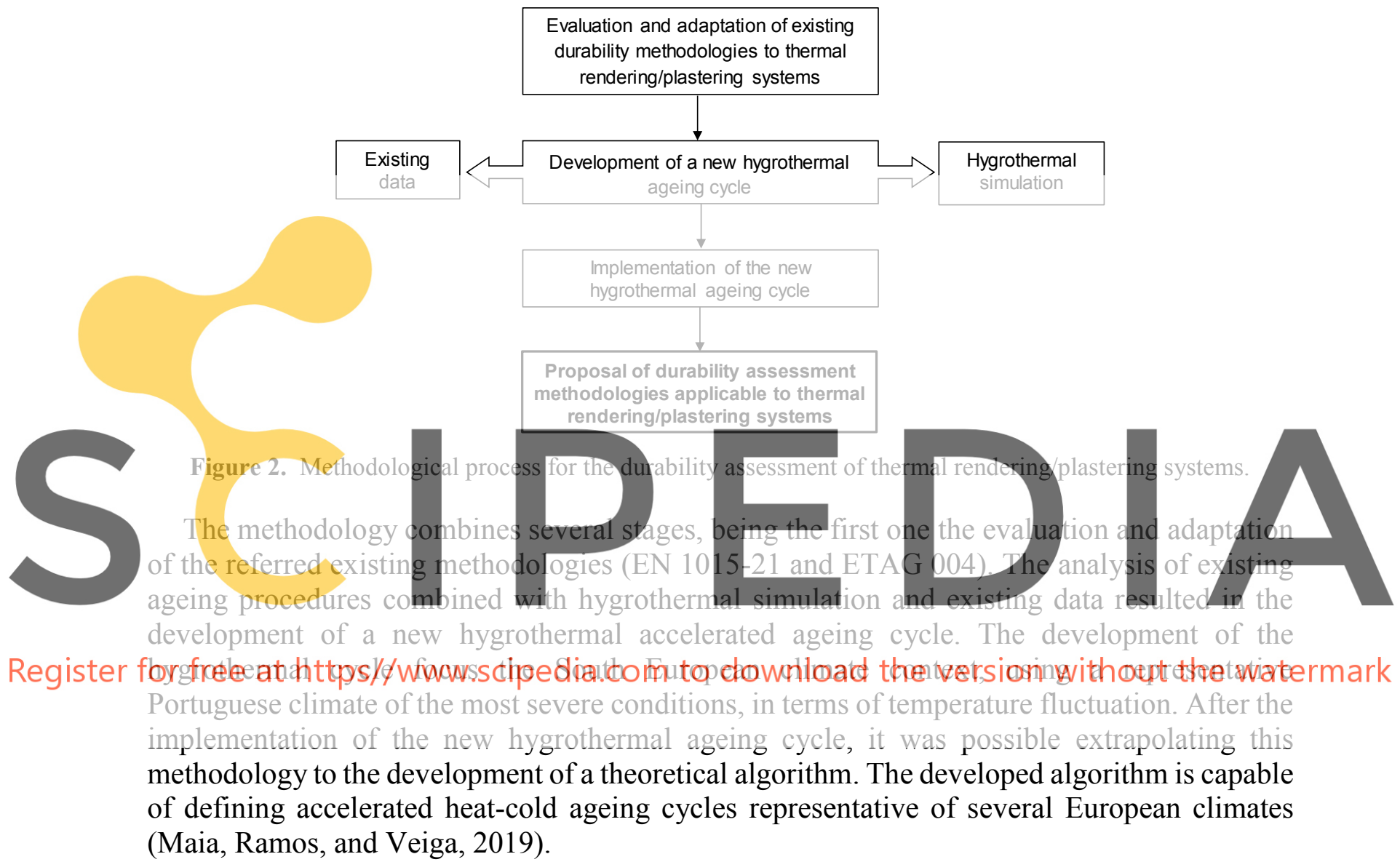

\section{Durability Assessment of Thermal Mortars - Experimental Methodology}

Figure 3 presents the adopted experimental methodology to evaluate the durability assessment of thermal rendering and plastering systems. The first step consists in the adaptation of existing methodologies, such as the envisaged in EN 1015-21 and ETAG 004, using small-scale specimens. The EN 1015-21 methodology includes heating-freezing and humidificationfreezing ageing cycles and the ETAG 004 freeze-thawing cycles. The evaluation of the existing procedures allowed understanding the gaps, disadvantages and advantages of implementing such methodologies to thermal rendering and plastering systems. The second step consists in the implementation of a new accelerated ageing hygrothermal cycle adapted to thermal rendering systems, through hygrothermal simulation and previous knowledge of the existing 
methodologies. Being the location where the system is intended to be applied, one of the main aspects to take into consideration in the durability assessment, the wide range of existing climates should be considered (Juaristi, Gómez-Acebo, and Monge-Barrio, 2018; Perino and Serra, 2015). In the present work, the European climatic context, which combines very different conditions, was analysed. Köppen-Geiger climate classification is one of the most used and well-known and classifies according to the main climate, precipitation and temperature (Kottek, Grieser, Beck, Rudolf, and Rubel, 2006). Focusing on the European context, the EOTA (1999) Guidance Document classifies the climatic zones according to the air temperature and the solar energy intensity. Analysing different European climates, a tendency from the lower to the higher latitudes was observed, being more representative of zones $\mathrm{C}$ to A, respectively. In that way, freeze-thaw may have a more relevant impact in northern climates, while thermal shock, originated by the incidence of cold rain in warm surfaces, in southern climates. In terms of internal environment, EOTA (1999) groups four sub-divisions, due to specific conditions to which the buildings are subjected: a) Temperature: heating, non-heating, refrigerating, localised radiation, etc.; b) Humidity: dry or wet conditions; c) Liquid water: permanently wet (e.g. bathrooms); and d) Chemicals: cleaning, cooking and special conditions in laboratories, hospitals, etc.. Figure 4 summarises the different stages of the durability assessment methodology and the sequencing between them.
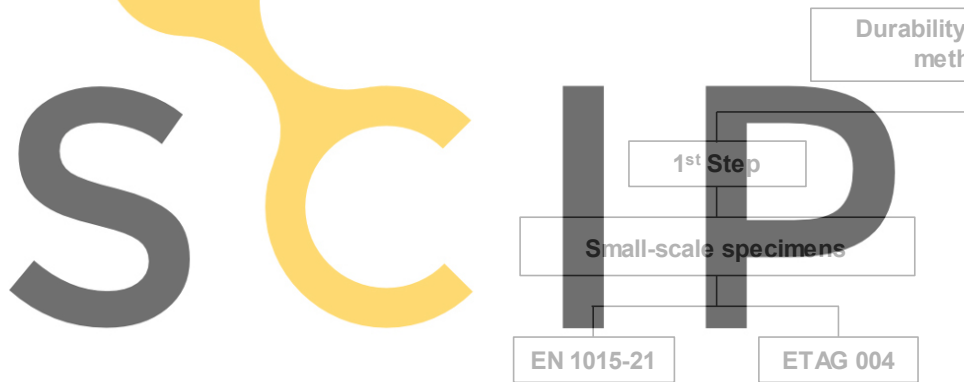

Drability experimental methodology
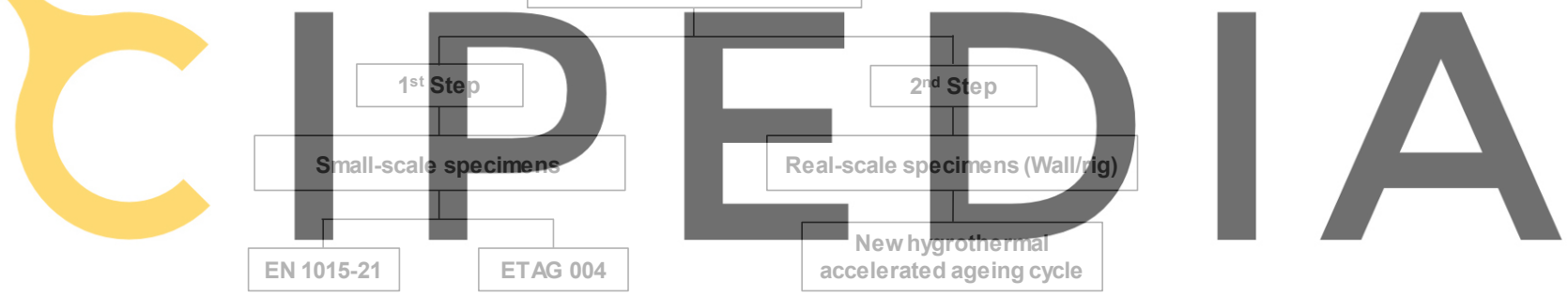

Register for free at https//www.scipedia.com to download the version without the watermark Figure 3. Durability experimental methodology.

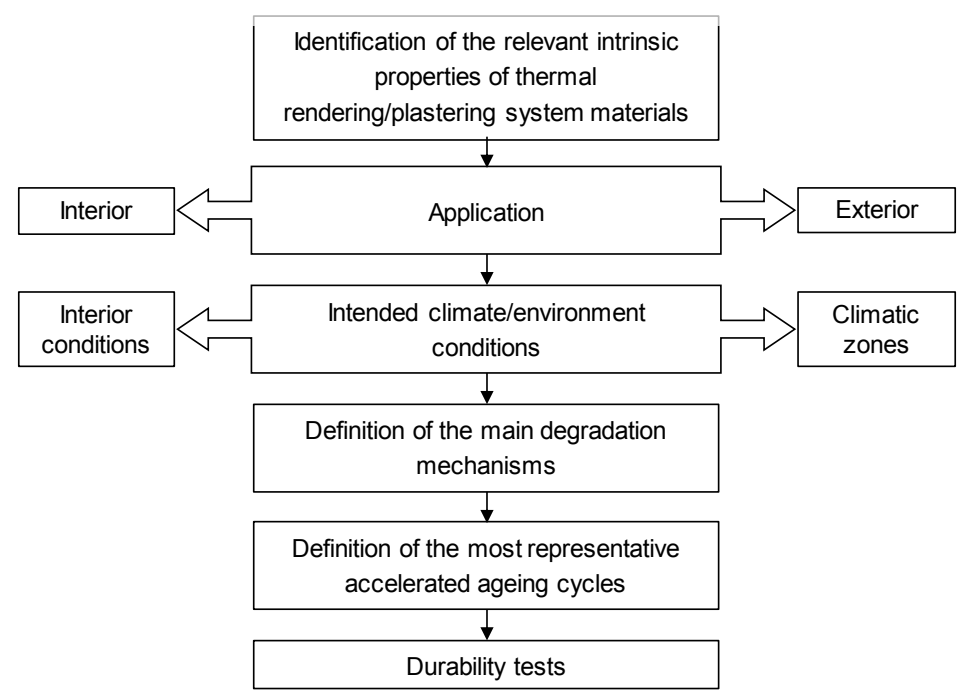

Figure 4. Durability assessment methodology. 


\section{An Integrated Durability Assessment Methodology Applicable to Thermal Mortars in Multi-layer Systems}

\subsection{General Methodology}

The development of methodologies that reproduce the most relevant degradation mechanisms in thermal rendering and plastering systems were performed. According to the requirements applicable to thermal mortars and considering their relevant properties, a methodology regarding the application of the thermal mortars in multi-layer systems is presented in Figure 5. The knowledge of the physical and hygrothermal behaviour of the referred systems is based on the work developed in Maia, Ramos, and Veiga (2018).

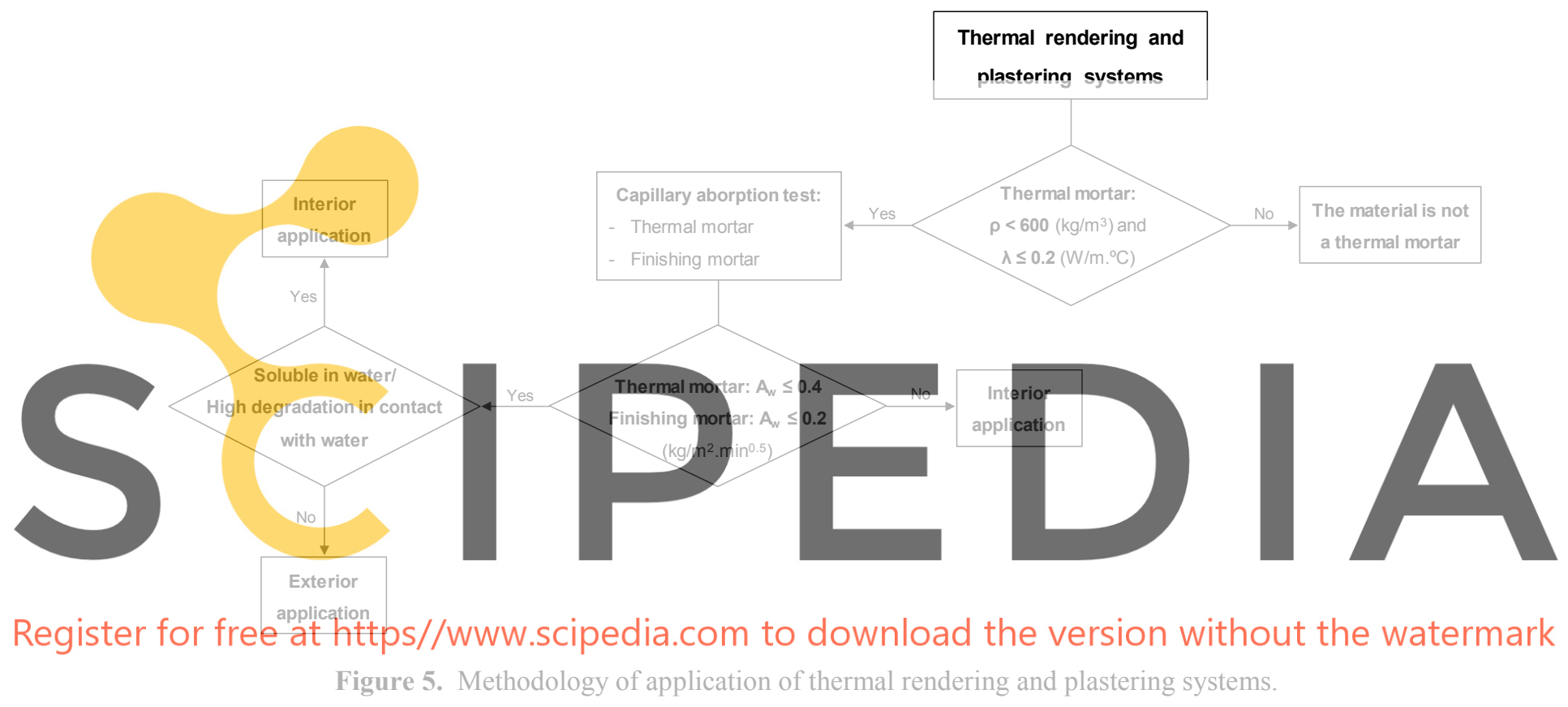

\subsection{Durability Assessment Methodology Applicable to Thermal Plastering Systems}

Despite the little development of the durability assessment of thermal plastering systems, the implementation of EN 1015-21 ageing cycles allows observing the degradation of the system performance. As such, a preliminary proposal of a durability assessment methodology applicable to thermal plastering systems, regarding the interior application, is presented in Figure 6. The capillary absorption requirement is supported by the capillary classes defined in EN 998-1 (CEN, 2010). The heating $\left(60^{\circ} \mathrm{C}\right)$-freezing $\left(-15^{\circ} \mathrm{C}\right)$ procedure (defined according to EN 1015-21 (CEN 2002a)), allows analysing the effect of the temperature fluctuation, regarding high-temperature variations. The application tof freezing conditions may be too severe for plastering systems applied in interior layers and may therefore be replaced by a higher minimum value adequately justified. However, the effect of humid environments, at high or low temperatures, was not evaluated and is a crucial aspect concerning the durability of plasters. In short, the application of thermal plastering systems requires an accurate analysis, regarding the environmental conditions where the system is intended to be applied, and the definition of the 
related ageing cycles (that should represent the environment as accurately as possible).
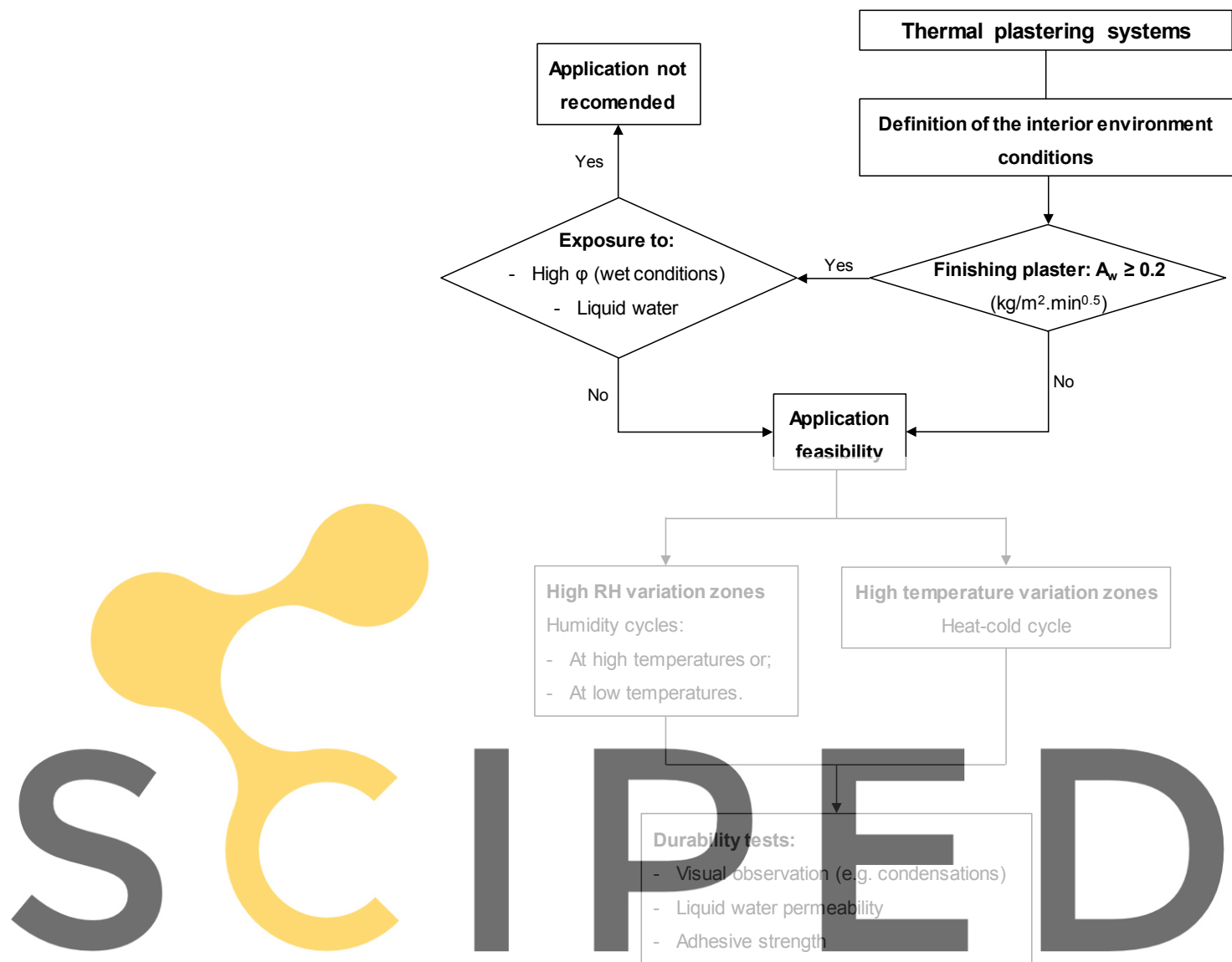

Register for free at https//Www. scipedia.com to download the version without the watermark

\subsection{Durability Assessment Viethodology Applicable to Thermal Rendering Systems}

The characteristics and durability of thermal rendering systems, suitable for the exterior application, were already presented in the previous work of Maia et al. (2019). The developed methodology, applicable to thermal rendering systems, combines the previous knowledge of the requirements and material properties (obtained by experimental tests and numerical simulation) with a detailed durability experimental campaign. This campaign preconizes the implementation of several accelerated ageing tests, taking into account the relevant degradation mechanisms. To a better adequacy of the durability assessment to thermal rendering systems, a new hygrothermal ageing cycle, which combines heat-cold and heat-rain cycles regarding the Portuguese climatic, was developed through climate analysis and hygrothermal simulation, with WUFI Pro software (IBP, 2018). The heat-cold cycle comprises a cold period $\left(-5^{\circ} \mathrm{C}\right.$ for $11 \mathrm{~h})$, a warm period $\left(65^{\circ} \mathrm{C}\right.$ for $\left.7 \mathrm{~h}\right)$ and the transitions between the 2 stages, resulting in a $24 \mathrm{~h}$ cycle. The heat-rain cycle comprises a warm period $\left(70{ }^{\circ} \mathrm{C}\right.$ for $\left.2 \mathrm{~h}\right)$, a rain period $\left(15^{\circ} \mathrm{C}\right.$ and $11 / \mathrm{m}^{2}$.min. of water spraying, for $1 \mathrm{~h}$ ) and the transitions between the 2 stages, resulting in a $6 \mathrm{~h}$ cycle, repeated 80 times. This first approach allowed the development of a theoretical 
methodology for the definition of heat-cold cycles in the European context (Maia et al., 2019).

\section{Conclusions}

The existing durability assessment procedures of thermal mortars showed to be insufficient to a precise and realistic evaluation. In that way, the authors developed a new durability assessment methodology, based on real material characteristics and the performance of the system as a whole. The developed methodology highlighted the importance of combining different evaluation methods, such as numerical simulation and experimental tests (existing and new procedures). The previous knowledge of the application requirements allowed the definition of different paths regarding the main degradation mechanisms and, consequently, the most representative accelerated ageing cycles. The main degradation mechanisms include high temperature variations, high relative humidity variations, exposure to high relative humidity, exposure to liquid water and freeze-thaw. The presence of liquid water and high relative humidity is a key factor for the decision on the applicability conditions of thermal mortars. A high water absorption of both the thermal mortar and the finishing layers, in multilayer systems, will define the limitation to interior applications only.

In summary, the implementation of the standard procedures to different thermal rendering and plastering systems allowed understanding the deterioration caused by each degradation mechanism. The acquired knowledge contributed to the development of the hygrothermal ageing cycles since the relevant gaps were identified and bridged. The several experimental

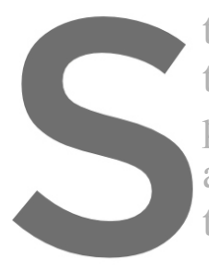
tests, performed befor thermal renders/plasters properties and perfo assessment methodolo the developed hygrothermal cycter.
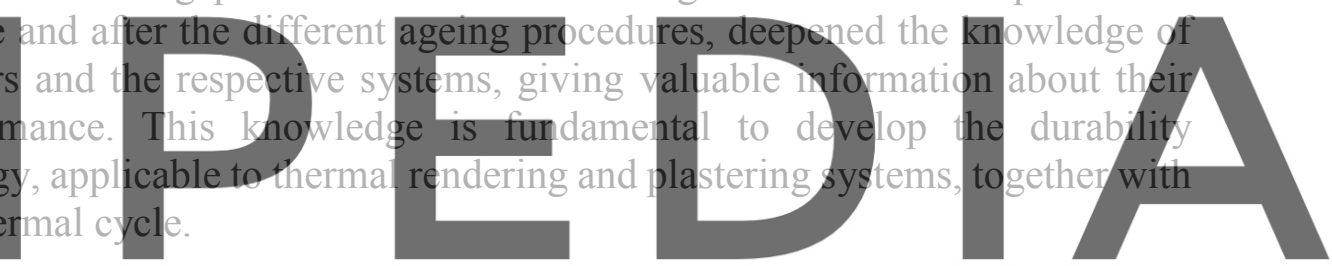

Acknowledgements

Register for free at htths / www scipedia. som to downdoad the version without the watermark

Doctoral Programme EcoCoRe of FCT - Fundação para a Ciência e a Tecnologia. This work was financially supported by Project PTDC/ECICON/28766/2017 - POCI-01-0145-FEDER-028766 funded by FEDER funds through COMPETE2020 - Programa Operacional Competitividade e Internacionalização (POCI) and by national funds (PIDDAC) through FCT/MCTES and the Project Reuse - Rehabilitation and Sustainability, supported by LNEC. This work was financially supported by: UID/ECI/04708/2019- CONSTRUCT - Instituto de I\&D em Estruturas e Construções funded by national funds through the FCT/MCTES (PIDDAC). The authors also acknowledge to Saint-Gobain Weber, Secil Argamassas and Sival - Gessos Especiais to the materials supply.

\section{ORCID}

Joana Maia: https://orcid.org/0000-0001-5036-8581

Nuno M. M. Ramos: https://orcid.org/0000-0002-5331-7429

Rosário Veiga: https://orcid.org/0000-0002-7135-8603

\section{References}

ABCB. (2006). Durability in Buildings. Handbook.

Borges, A., Flores-Colen, I. and de Brito, J. (2018). Physical and mechanical performance of cement-based renders with different contents of fly ash, expanded cork granules and expanded clay. Construction and Building Materials, 191, 535-543. doi:10.1016/j.conbuildmat.2018.10.043 
CEN. (2002). EN 1015 Methods of test for mortar for masonry. In Part 21: Determination of the compatibility of one-coat rendering mortars with substrates. Brussels: European Commitee for Standardization.

CEN. (2010). EN 998 Specification for mortar for masonry. In Part 1: Rendering and plastering mortar. Brussels: European Commitee for Standardization.

EMO. (2013). Goal 6. Retrieved from http://www.euromortar.com/7-goals/6-creating-awareness-forsustainability/

EOTA. (1999). Assessment of working life of products. In Guidance Document 003. Brussels: European Organisation for Technical Approvals.

EOTA. (2013). ETAG 004. In Guideline for European Technical Approval of External Thermal Insulation Composite Systems with Rendering. Brussels: European Organisation for Technical Approvals.

Erhorn, H., Hansen, J. O., Kaan, H. and Barker, M. (2007). What are Eco-Buildings and are they needed in the Seventh Framework Programme (FP7)? : BRITA in PUBs.

Gaspar, P. L. and Brito, J. d. (2008). Quantifying environmental effects on cement-rendered facades: A comparison between different degradation indicators. Building and Environment, 43(11), 1818-1828. doi:https://doi.org/10.1016/j.buildenv.2007.10.022

IBP. (2018). WUFI Postptocessor: Thermal conductivity. WUFI Pro Manual.

Juaristi, M., Gómez-Acebo, T. and Monge-Barrio, A. (2018). Qualitative analysis of promising materials and technologies for the design and evaluation of Climate Adaptive Opaque Façades. Building and Environment, 144, 482-501. doi:https://doi.org/10.1016/j.buildenv.2018.08.028

Kottek, M., Grieser, J., Beck, C., Rudolf, B. and Rubel, F. (2006). World Map of the Köppen-Geiger climate classification updated. Meteorologische Zeitschrift, 15(No.3), 259-263. doi:10.1127/09412948/2006/0130

Maia, J., Ramos, N. M. M. and Veiga, R. (2018). Evaluation of the hygrothermal properties of thermal rendering systems. Building and Environment, 144, 437-449. doi:https://doi.org/10.1016/j.buildenv.2018.08.055

Maia, J., Ramos, N. M. M. and Veiga, R. (2019). A new durability assessment methodology of thermal mortars applied in multilayer rendering systems. Construction and Building Materials, 222, 654-663.
doi:10.1016/j.conbuildmat.2019.06.178
G., Faria, P. and Torres, I. (2014). Lime mortars with ceramic wastes: Characterization of components and
their influence on the mochanical behaviour. Construction and Building Materials, 73, $523-534$.
doi:http:/dx.doi.org/10.1016/j. conbuildmat.2014.09.108
R. H. and Berardi.U. (2018). Hygrothermal characteristics of aerogel-enhanced insulating materials under different humidity and temperature conditions. Energy and Buildings, 158, 698-711. doi:10.1016/j. enbuild.2017.09.079

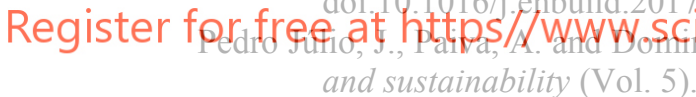

Perino, M. and Serra, V. (2015). Switching from static to adaptable and dynamic building envelopes: A paradigm shift for the energy efficiency in buildings. Journal of Facade Design and Engineering(2), 143-163\%V 143. doi:10.7480/jfde.2015.2.1015

Skoczylas, K. and Rucińska, T. (2018). The effects of waste glass cullets and nanosilica on the long-term properties of cement mortars. E3S Web Conf., 49, 00102.

Soares, A., de Fátima Júlio, M., Flores-Colen, I., Ilharco, L. M. and Brito, J. D. (2018). EN 998-1 performance requirements for thermal aerogel-based renders. Construction and Building Materials, 179, 453-460. doi:10.1016/j.conbuildmat.2018.05.197

Torres, I. and Matias, G. (2016, 16-17 June). Waste recovery to integration in renders. Paper presented at the Argamassas 2016 - Symposium on Mortars and Thermal Coating Solutions, Coimbra, Portugal.

Westgate, P., Paine, K. and Ball, R. J. (2018). Physical and mechanical properties of plasters incorporating aerogel granules and polypropylene monofilament fibres. Construction and Building Materials, 158, 472-480. doi:10.1016/j.conbuildmat.2017.09.177 